\title{
New insights into the reactivity of 2-halo-glycals. Synthesis of novel iodinated 0- and S-glycosides
}

Agustín H. Rojas, ${ }^{a}$ Leticia Lafuente, ${ }^{a}$ Virginia Vetere, ${ }^{\text {b* }}$ Agustín Ponzinibbio ${ }^{\text {a* }}$

a Centro de Estudio de Compuestos Orgánicos, CEDECOR (CIC - UNLP). Departamento de Química, Facultad de Ciencias Exactas, Universidad Nacional de La Plata, 47 y 115, 1900 La Plata, Argentina.

b Centro de Investigación y Desarrollo en Ciencias Aplicadas "Dr. Jorge J. Ronco", CINDECA (CONICET-CCT- La PlataUNLP), Universidad Nacional de La Plata, Facultad de Ciencias Exactas, calle 47 n 257, 1900, La Plata, Argentina.

* Corresponding authors: V. Vetere (vetere@quimica.unlp.edu.ar) and A. Ponzinibbio (ponzinibbio@quimica.unlp.edu.ar)

Dedicated to Professor Rodolfo Bravo on occasion of his retirement

Key words: 2-iodo-glycals; Ferrier rearragement; S-glycosides, NMR; conformations

Abstract: This is the first report on the Ferrier rearrangement of 2-halo-glycals with S-nucleophiles. We present herein the selective synthesis of new 2-iodo-2,3-unsaturated $O$ - and S-glycosides. We obtained in good yields and high anomeric selectivity $\alpha$-glycosydes. As a particular behaviour, we also describe heteroaromatic thio sugar derivatives were the $C 3$ addition was performed in an alternative mechanism. A complete structure and conformation analysis by NMR was also presented.

In the last decades, the synthesis and reactivity of 2-halo glycals have emerged as a unique field of organic synthesis to access novel carbohydrate derivatives. [1] In particular, the reactivity via metalcatalyzed cross-coupling reactions was studied. [2] This methodology allows obtaining 2-C branched glycosides, a new class of sugar derivatives, with promising biological activity. [3] Few reports were detected in the literature on the reactivity of this 2-substituted glycals with nucleophiles and acid catalysis. Dharuman and Vankar reported for the first time the Ferrier rearrangement of D-glucose and D-galactose iodinated derivatives with three different alcohols. [4] More recently Dong et al., complement the previous cited work, using a new heterogeneous catalyst. Several alcohols were added in a Ferrier fashion to D-glucose unsaturated derivatives using a magnetic iron catalyst.[5]

In the present work, we investigated the reactivity of 2-iodo-glycals derived from D-glucose and Dgalactose with different nucleophiles. As part of our recent efforts to obtain biologically active glycosyl derivatives [6] at first, we decided to obtain new O-derivatives that were not reported with the methodology previously cited. [4] Then we explore the reactivity of 2-iodo-glycals with S-nucleophiles. The importance of thioglycosides as biologically active compounds was demonstrated throughout the years. [7] The S-sugar moiety has been found in several natural products, active drugs and enzymatic inhibitors. [8] For the reasons described, the synthesis of thioglycosides from 2-haloglycals is an unexplored field that may allow obtaining promising bioactive compounds.

As previously stated we decided to synthetized new O-glycosides from the acid-catalyzed additions of $\mathrm{OH}$ nucleophiles to 2-haloglycals. Because of the particular structure, that allows them to act as synthons for the synthesis of more complex glycosides, we use decanediol and $\mathrm{N}$-hydroxysuccinimide as nucleophiles. The latter is particularly interesting because they are useful substrates to construct hydrolytically stable -O-N- glycosides [9] 
As expected, we obtain the desired products with high anomeric selectivity and good yields from both erythro and threo derivatives. Then we tested the reactions with (-)-menthol and cholesterol that were only reported in the literatura for the D-glucose series. [5] Satisfactory results were also obtained, good yields and high anomeric selectivity are reported in all studied cases. We resume the results in Table 1.

Table 1.

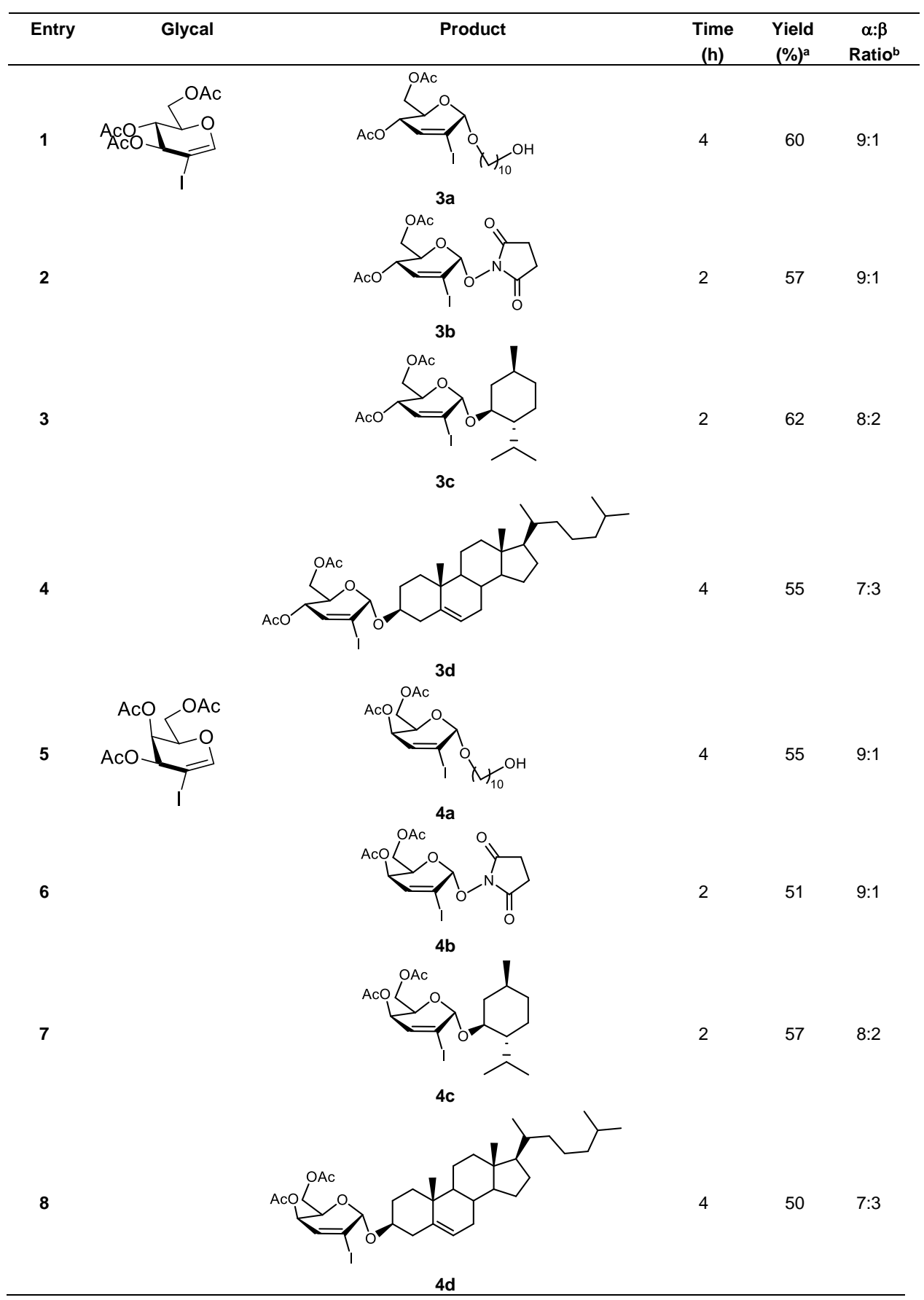

${ }^{a}$ Anomeric ratio was determined by ${ }^{1}$ HNMR Spectroscopy of crude products. ${ }^{b}$ Calculated after purification of crude product.

In conclusion, we obtain six new iodinated 2,3-unsaturated-O-glycosides in good yields and high stereoselectivity. Their structures were fully characterized by NMR spectroscopy. The NMR's spectra were undoubtedly resolved and all data obtained were similar to previously reported comparable structures. Some structural and conformational characteristics, extracted from NMR data, are important 
to be mention. The anomeric configuration was $\alpha$ in all cases, as expected when $\mathrm{BF}_{3} . \mathrm{OEt}_{2}$ catalyst was used. This anomeric configuration was confirmed by the absence of NOE effect between $\mathrm{H} 1$ and $\mathrm{H} 5$ protons. Also, we have crystallographic data for similar structures obtained in equal reaction conditions that confirm this hypothesis.[10] As two conformations may be present in 2,3-unsaturated systems, ${ }^{5} \mathrm{H}_{0}$ and ${ }^{0} \mathrm{H}_{5}$, we analyzed the ${ }^{3} \mathrm{~J}_{4,5}$ coupling constants to elucidate the preferred one. The values obtained $\mathrm{J}>9.00 \mathrm{~Hz}$ in the D-glucose derivatives, were indicative of a di axial orientation of the vicinal protons, in consequence, the ${ }^{0} \mathrm{H}_{5}$ form was majority adopted in $\mathrm{CDCl}_{3}$ solution. (Figure $1 \mathrm{~A}$ )
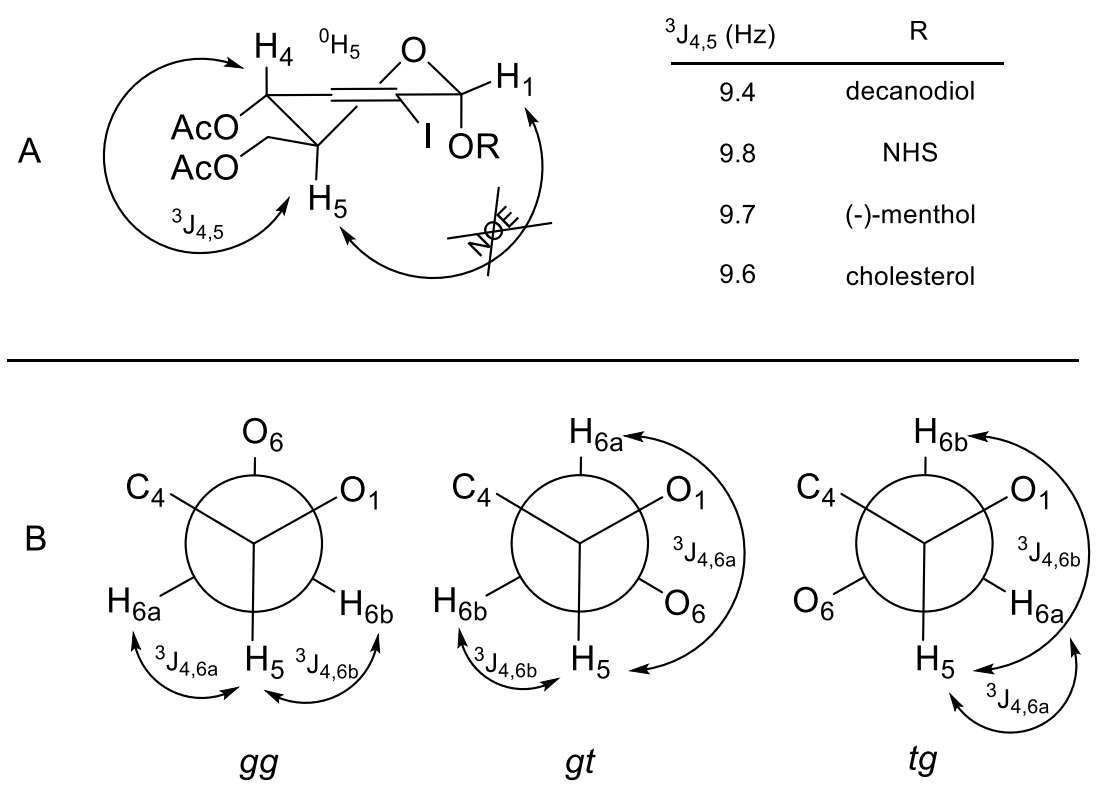

Figure 1. Possible conformations in the pyranose unsaturated cycle $(A)$ and around the acetoxymethyl C5-C6 bond (B).

As previously described by us the acetoxymethyl (C6) moiety may adopt different conformations as seen in Figure 1B and, in solid-state $g g$ and $g t$ were the preferred ones. The latter was the more abundant in a CSD search performed, approximately $70 \%$ of the structures adopt this conformation. [11] The ${ }^{3} J_{5,6 a}$ and ${ }^{3} J_{5,6 b}$ coupling constants are indicative of this conformations. [12] The values obtained in the molecules prepared by us are in the range of $2.5-3.0$ and $5.0-5.5 \mathrm{~Hz}$ respectively. According to reported formulas, derived from the Karplus equation, that correlates the $\mathrm{J}$ values with torsion angles the $g g$ conformation was the most significant in $\mathrm{CDCl}_{3}$ solution for our new reported 2haloglycosydes.

With these good preliminary results in hand, we decided to explore the synthesis of S-glycosides with the same methodology. The addition of several S-nucleophiles were tested and the results are summarized in Table 2. 
Table 2

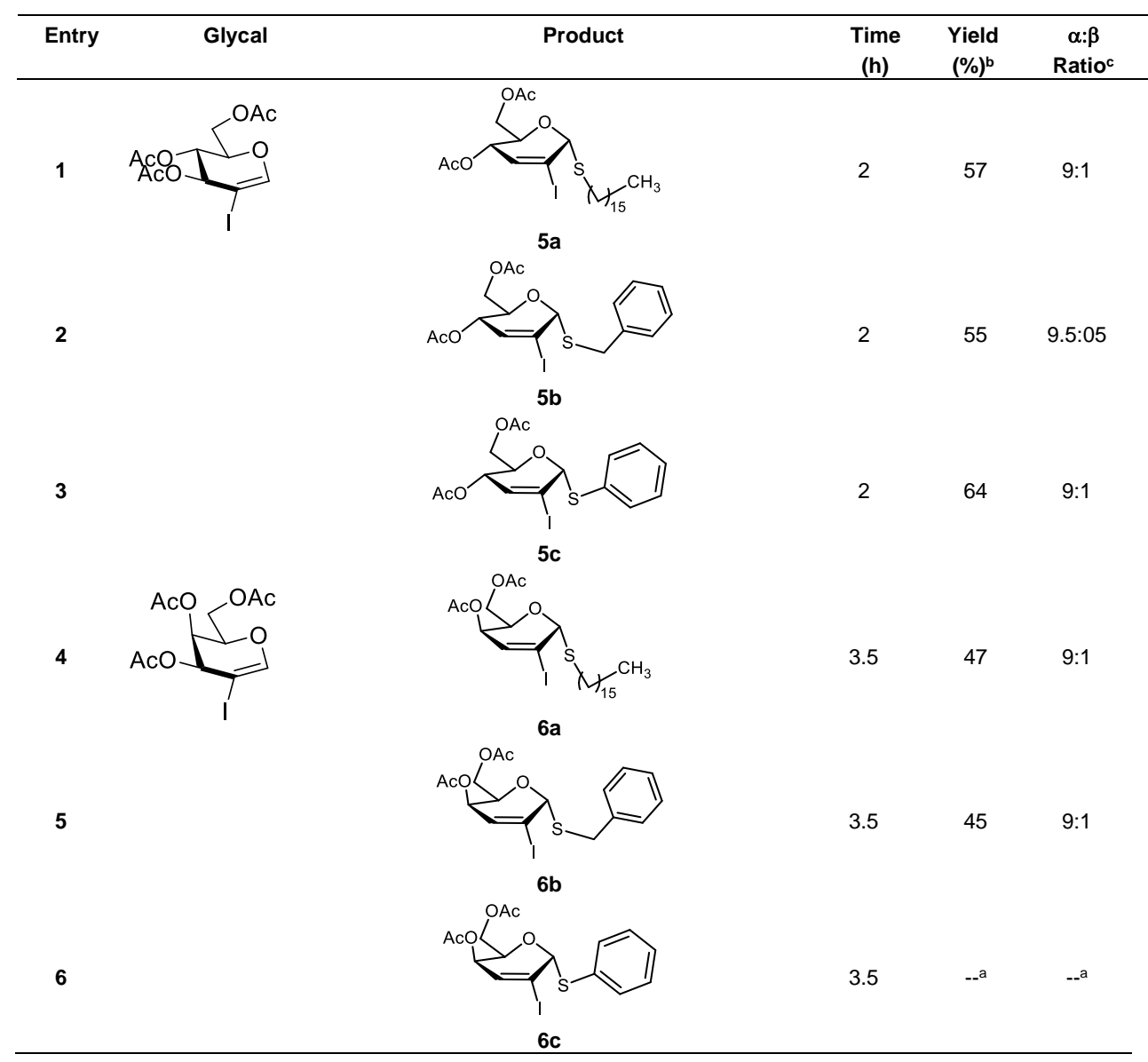

a A mixture of products was obtained and we couldn't purify it properly. ${ }^{b}$ Anomeric ratio was determined by ${ }^{1} \mathrm{HNMR}$ Spectroscopy of crude products. ${ }^{\mathrm{C}}$ Calculated after purification of crude product.

As seen in entry 6 we obtain the desired product impure. We could not achieve a good chromatography purification. Analyzing the NMR spectra we detected the presence of a minor by-product. Because of good signal separation in the ${ }^{13} \mathrm{C}$ NMR and with the aid of gHSQC experiment, we were able to identify the impurity. The thiophenol was also added to C3, with an alternative mechanism, generating a subproduct. (Figure 2)

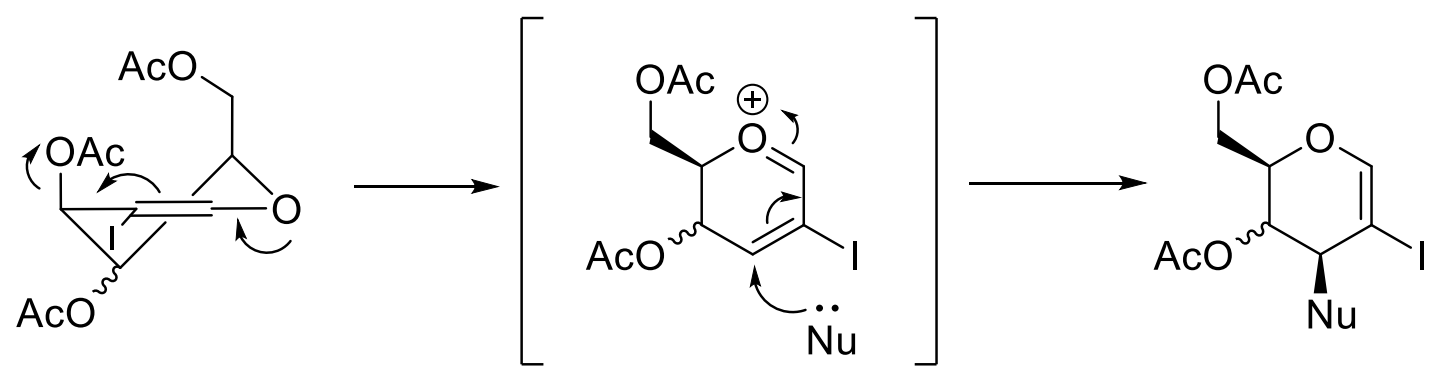

Figure 2. Proposed mechanism for the S-nucleophilic addition to C3 2-iodo-glycals.

As heterocyclic moieties were revealed as transcendentals in many bioactive glycosyl derivatives, we try to incorporate 2-mercaptobenzothiazole to the 2-halo carbohydrate. Surprisingly we obtained the C3 addition derivatives, $\mathbf{5 d}$ and $\mathbf{6} \mathbf{d}$, as a major products. Their structures were fully characterized by ${ }^{1} \mathrm{H}$ and ${ }^{13} \mathrm{C}$ NMR. Analyzing and comparing the coupling constants within protons 3 and 4 for both threo 
and erythro D-glycals we could presume that the S-nucleophile has been added at C3 from the upper face of the sugar. These results were similar to the obtained by Vankar when tiophenol or azide were added to 2-nitroglycals. [13] Figure 3
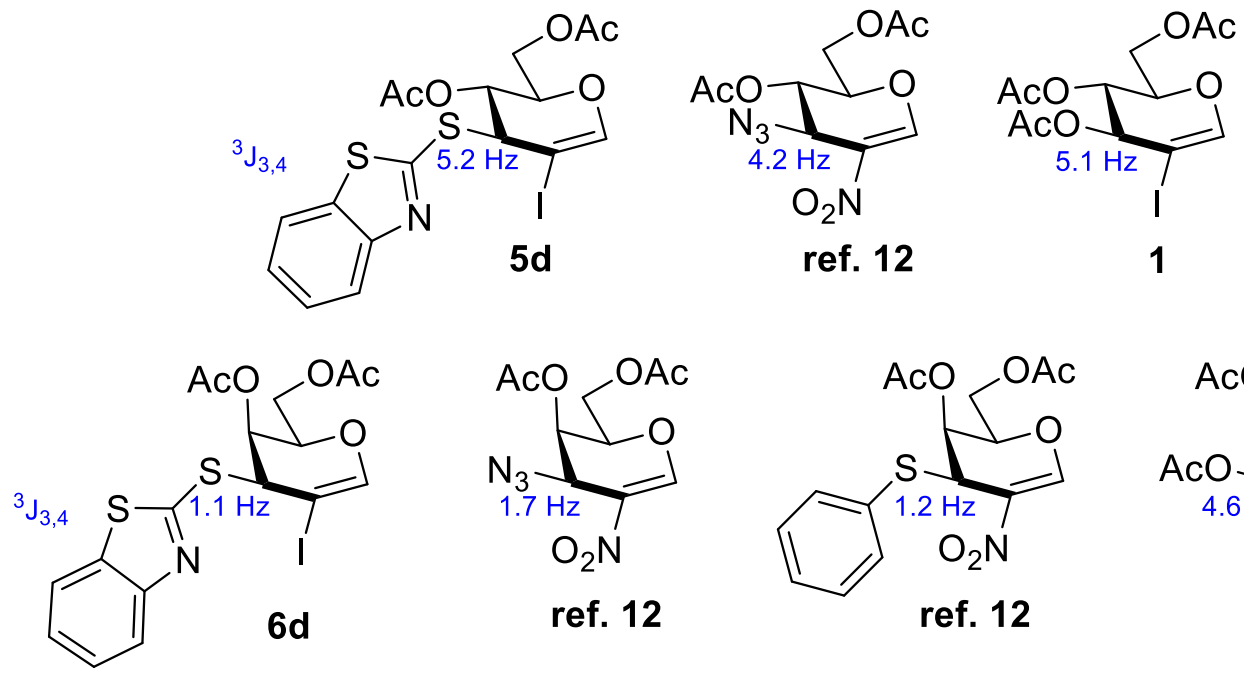

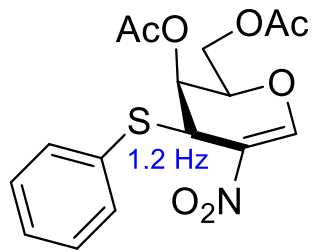

ref. 12

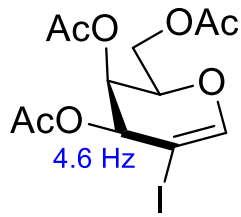

2

Figure 3. 3-substituted 1,2-unsaturated glycosides and their indicative ${ }^{3} \mathrm{~J}_{3,4}$ values.

As seen en Figure 3 the ${ }^{3} J_{3,4}$ were similar in all cases. In the range of $4-5 \mathrm{~Hz}$ for compounds derived from $\mathrm{D}$-glucose and $1-2 \mathrm{~Hz}$ when the $\mathrm{C} 4$ has the opposite configuration. We only appreciate a significant difference when the $\mathrm{C} 3$ was substituted with oxygen versus nitrogen or sulfur moieties. This may indicate a change in conformations prevalences or a differentiation in the typical axial-equatorial bond angles. Unfortunately, we couldn't obtain a sample suitable for X-ray analysis. We are currently working on expanding the library of S-glycosides and expecting a single crystal may be obtained.

In conclusion, we have obtained in good yields and high anomeric selectivity 14 new unsaturated 2iodo glycosides. The Ferrier rearrangement of 2-halo glycals derived from D-galactose and D-glucose was successfully performed. We report new O-glycosides to complete the few reports on this theme done. In this work, we described for the first time the synthesis of new thio-glycosydes via the addition of S-nucleophiles to C1 and C3 centres of 2-iodo glycals. The analysis of NMR data reveals some conformation characteristics and of course, the undoubted structure of the novel molecules synthesized.

\section{Acknowledgment}

Authors wish to thank CICPBA, UNLP, CONICET and ANPCyT of Argentina for financial support. We express deep thanks to Omar E. Guaymás (CICPBA) for assistance in the preparation and NMR characterization of some compounds and Rodolfo Bravo (UNLP retired) for valuable advice. A. P. and V. V. are Research Fellows of CONICET. 


\section{References}

[1] a) S. R. Chemler, U. Iserloh, S. J. Danishefsky, Org. Lett. 2001, 3, 2949- 2951 b) M. A. Rodriguez, O. Boutureira, M. I. Matheu, Y. Diaz, S. Castillon, P. H. Seeberger, J. Org. Chem. 2007, 72, 8998-9001; c) I. Cobo, M. I. Matheu, S. Castillon, O. Boutureira, B. G. Davis, Org. Lett. 2012, 14, 1728- 1731 d) S. Jana, J. D. Rainier, Org. Lett. 2013, 15, 4426- 4429; e) S. Dharuman, Y. D. Vankar, Org. Lett. 2014, 16, 1172- 1175 f) A. Shamim, S. N. S. Vasconcelos, B. Ali, L. S. Madureira, J. Zukerman-Schpector, H. A. Stefani, Tetrahedron Lett. 2015, 56, 5836- 5842; g) A. Bordessa, A. Ferry, N. Lubin-Germain, J. Org. Chem. 2016, 81, 12459-12465; h) A. Shamim, C. S. Barbeiro, B. Ali, H. A. Stefani, ChemistrySelect 2016, 1, 56535659. i) A. Shamim, F. B. Souza, S. N. S. Vasconcelos, H. A. Stefani, Tetrahedron Lett. 2017, 58, 884- 888; j) R. A. A. AlShuaeeb, D. Montoir, M. Alami, S. Messaoudi, J. Org. Chem. 2017, 82, 6720-6728; k) W. Fan, Y. Chen, Q. Lou, L. Zhuang, Y. Yang, J. Org. Chem. 2018, 83, 6171-6177; I) N. Hussain, M. Bhardwaj, A. Ahmed, D. Mukherjee, Org. Lett. 2019, 21, 3034- 3037. m) M. P. Darbem, K. S. Kanno, I. M. de Oliveira, C. H. A. Esteves, D. C. Pimenta, H. A. Stefani, New J. Chem. 2019, 43, 696-699; n) A. Ahmed, N. Hussain, M. Bhardwaj, A. K. Chhalodia, A. Kumar, D. Mukherjee, RSC Adv. 2019, 9 , 22227-22231; o) M. de Robichon, A. Bordessa, N. Lubin-Germain, A. Ferry, J. Org. Chem. 2019, 84, 3328- 3339; p) J. Liu, P. Han, J.-X. Liao, Y.-H. Tu, H. Zhou, J.-S. Sun, J. Org. Chem. 2019, 84, 9344- 9352; q) H. A. Esteves, M. P. Darbem, D. C. Pimenta, H. A. Stefani, Eur. J. Org. Chem. 2019, 7384- 7388.

[2] Malinowski, M., Van Tran, T., de Robichon, M., Lubin-Germain, N., Ferry, A. Adv. Synth. Catal., 2020, 362 (5), pp. 11841189 and references cited therein.

[3] a) Yang, Y.; Yu, B. Chem. Rev. 2017, 117, 12281-12356. b) Awan, S.I.; Werz, D. B. Org. Biomol. Chem.2012, 20, 1846-1856. c) Vankar, Y. D.; Linker, T. Eur. J. Org. Chem. 2015, 2015, 7633-7642. d) Li, W.; Silipo, A.; Molinaro, A.; Yu, B. Dubbu,S.; Verma, A. K.; Parasuraman, K.; Vankar, Y. D. Carbohydr. Res. 2018, 465, 29-34.

[4] S. Dharuman, Y. D. Vankar. Org. Lett. 2014, 16, 1172-1175

[5] Dong, Y., Ding, Z., Guo, H., Zhou, L., Jiang, N., Chen, H., Qiu, S., Xu, X., Zhang, J. Synlett, 2019,30 (12), $1419-1426$.

[6] a) Santiago, C. C.; Lafuente, L.; Ponzinibbio, A. ChemistrySelect, 2020, 5, 4928-4931. b) Lafuente, L.; Santiago, C. C.; Rojas, A. H.; Piro, O. E.; Echeverría, G. A.; Ponzinibbio, A. ChemistrySelect, 2020, 5,864-868. c) Rojas, A. H.; Garritano Zendri, L.; Lafuente, L.; Ponzinibbio, A.; Vetere, V. ChemistrySelect 2019, 4, 14228-14232. d) Lafuente, L.; Rochetti, F.; Bravo, R.; Sasiambarrena, L.; Santiago, C.; Ponzinibbio, A. Lett. Org. Chem. 2019, 16, 447-453. e) Santiago, C.; Lafuente, L.; Bravo, R.; Díaz, G.; Ponzinibbio, A. Tetrahedron Lett. 2017, 58, 3739-3742. f) Lafuente, L.; Díaz, G.; Bravo, R.; Ponzinibbio, A. Lett. Org. Chem. 2016, 13, 195-200. g) Díaz, G.; Ponzinibbio, A.; Bravo, R. Carbohydr. Res. 2014, 393, 2325.

[7] a) K. Pachamuthu, R. R. Schmidt, Chem. Rev. 2006, 106, 160-187; b) M. Samuni-Blank, I. Izhaki, M. D. Dearing, Y. Gerchman, B. Trabelcy, A. L. W. H. Karasov, Z. Arad, Curr. Biol. 2012, 22, 1218-1220. c) G. Lian, X. Zhang, B. Yu, Carbohydr. Res. 2015, 403, 13-22

[8] a) J. Rodriguez, G. Ganne, B. Blanchard, C. Saucier, D. Giguere, T. C. Shiao, A. Varrot, A. Imberty, R. Roy, Org. Biomol. Chem. 2013, 11, 6906-6918; b) G. H. Elgemeie, A. B. Farag, K. M. Amin, O. M. El-Badry, G. S. Hassan, Med. Chem. 2014, 4, 814-820; c) M. R. Aouad, Nucleosides Nucleotides Nucleic Acids 2016, 35, 1-15

[9] N. Chen, J. Xie. Org. Biomol. Chem., 2016, 14, 11028-11047

[10] Unpublished results. Crystallographic structural data have been deposited at the Cambridge Crystallographic Data Centre (CCDC). Any request to the Cambridge Crystallographic Data Centre for this material should quote the reference number CCDC 1986507.

[11] L. Lafuente, A. H. Rojas, O. E. Piro, G. A. Echeverría, A. Ponzinibbio. Synthesis, NMR and X-ray studies on aminooxylated carbohydrates. Preparation and structure of novel heteroaromatic 2-deoxy-O-N-glycosides. Unpublished results.

[12] M. Tafazzoli; M. Ghiase. Carbohydrate Res. 2007, 342, 2086-2096

[13] Dharuman, S., Gupta, P., Kancharla, P. K., \& Vankar, Y. D. J. Org. Chem. 2013, 78(17), 8442-8450. 


\section{Supplementary Information}

\section{A)Experimental procedures}

Synthesis of 3,4,6-tri-O-acetyl-2-iodo-D-glucal and 3,4,6-tri-O-acetyl-2-iodo-D-galactal (1 and 2): in a two-necked round-bottom flask was added $3.67 \mathrm{mmol}(1 \mathrm{gr})$ of 3,4,6-tri-O-acetyl-glycal, followed by $7 \mathrm{~mL}$ of dry $\mathrm{CH}_{3} \mathrm{CN}$, under nitrogen flow. The solution was heated up to $80^{\circ} \mathrm{C}$ and $4.44 \mathrm{mmol}(1 \mathrm{gr})$ of NIS and $2.94 \mathrm{mmol}(500 \mathrm{mg})$ of $\mathrm{AgNO}_{3}$ were added to the reaction mixture and kept with good stirring. After consumption of the substrate (monitored by TLC), the mixture was filtered through a sintered glass funnel and diluted with $\mathrm{CH}_{2} \mathrm{Cl}_{2}$. The round-bottom flask and $\mathrm{Agl}$ in the funnel were washed with $\mathrm{CH}_{2} \mathrm{Cl}_{2}$ and added to the rest of t0.185 he organic solution. This solution was transferred to a separatory funnel and washed with distilled water $(2 \times 20 \mathrm{~mL})$, saturated $\mathrm{NaHSO}_{3}$ solution $(1 \times 20 \mathrm{~mL})$ and $10 \% \mathrm{NaHCO}_{3}$ solution $(1 \times 20 \mathrm{~mL})$. The organic solution was dried over anhydrous $\mathrm{Na}_{2} \mathrm{SO}_{4}$, filtered and evaporated under vacuum. The crude mixture was purified by column chromatography using silical gel and $\mathrm{n}$ Hexane:AcOEt (7:3) mixture as eluent, furnishing our pure acetylated 2-iodoglycal with $50 \%$ yield for D-glucal and $56 \%$ yield for D-galactal

General procedure for the synthesis of 2-iodoglycosydes: in a round bottom flask was added 0.125 $\mathrm{mmol}$ of protected 2-iodoglycal $\mathbf{1}$ or $\mathbf{2}$, followed by $0.187 \mathrm{mmol}$ of the corresponding nucleophile. The mixture was dissolved in $2 \mathrm{~mL}$ of dry $\mathrm{CH}_{2} \mathrm{Cl}_{2}$ then 1.5 eq. of $\mathrm{BF}_{3}$. OEt2 was added and kept with stirring, at room temperature, under nitrogen flow. Once the substrate was fully consumed (monitored by TLC), the crude reaction mixture was transferred to a separatory funnel and quenched with $10 \% \mathrm{NaHCO}_{3}$ solution. After quenching, the mixture was washed with water and dried over anhydrous $\mathrm{Na}_{2} \mathrm{SO}_{4}$. The dry solution was then filtered and evaporated under vacuum. The crude product was purified by flash column chromatography with silica gel and n-Hexane:AcOEt (3:2 or 7:3) as eluent, furnishing pure products.

\section{B) NMR data, substrates}

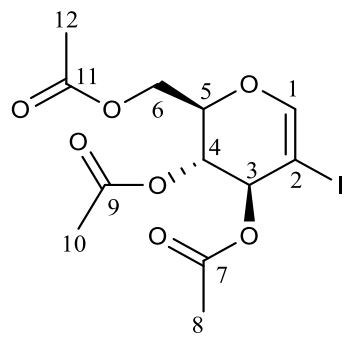

$\mathrm{Mp}=53^{\circ} \mathrm{C}-54^{\circ} \mathrm{C}$.

${ }^{1} \mathrm{H}-\mathrm{RMN}\left(600 \mathrm{MHz}, \mathrm{CDCl}_{3}\right): \delta(\mathrm{ppm})=2.09-2.13\left(\mathrm{~s}, 9 \mathrm{H}, \mathrm{H}^{8}, 10,12\right), 4.22$ (dd, $\left.\mathrm{J}=5.65 \mathrm{~Hz} ; 14.53 \mathrm{~Hz}, 1 \mathrm{H}, \mathrm{H}^{6}\right), 4.43\left(\mathrm{~m}, 2 \mathrm{H}, \mathrm{H}^{6} ; \mathrm{H}^{5}\right), 5.24\left(\mathrm{t}, \mathrm{J}=5.25 \mathrm{~Hz}, 1 \mathrm{H}, \mathrm{H}^{4}\right)$, $5.52\left(\mathrm{~d}, \mathrm{~J}=5.25 \mathrm{~Hz}, 1 \mathrm{H}, \mathrm{H}^{3}\right), 6.80\left(\mathrm{~s}, 1 \mathrm{H}, \mathrm{H}^{1}\right)$.

${ }^{13} \mathrm{C}-\mathrm{RMN}\left(151 \mathrm{MHz}, \mathbf{C D C l}_{3}\right): \delta(\mathrm{ppm})=20.7-20.8\left(\mathrm{C}^{8} ; \mathrm{C}^{10} ; \mathrm{C}^{12}\right), 60.9\left(\mathrm{C}^{6}\right), 66.3$ $\left(C^{2}\right), 67.6\left(C^{4}\right), 70.6\left(C^{3}\right), 74.0\left(C^{5}\right), 149.3\left(C^{1}\right), 169.3-170.4\left(C^{7} ; C^{9} ; C^{11}\right)$.

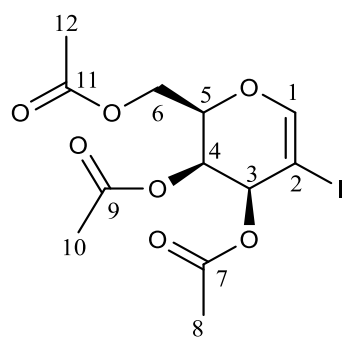

Mp: $106^{\circ} \mathrm{C}-107^{\circ} \mathrm{C}$.

${ }^{1} \mathrm{H}-\mathrm{RMN}\left(600 \mathrm{MHz}, \mathrm{CDCl}_{3}\right): \delta(\mathrm{ppm})=2.10-2.14\left(\mathrm{~s}, 9 \mathrm{H}, \mathrm{H}^{8}, 10,12\right), 4.21-4.28$ (dd, $\left.\mathrm{J}=7.5 \mathrm{~Hz} ; 11.8 \mathrm{~Hz}, 2 \mathrm{H}, \mathrm{H}^{6} ; \mathrm{H}^{6}\right), 4.45$ (tdd, J=1.1Hz; $\left.2.1 \mathrm{~Hz} ; 5.7 \mathrm{~Hz}, 1 \mathrm{H}, \mathrm{H}^{5}\right), 5.51$ $\left(\mathrm{dd}, \mathrm{J}=2.1 \mathrm{~Hz} ; 4.6 \mathrm{~Hz}, 1 \mathrm{H}, \mathrm{H}^{4}\right), 5.61\left(\mathrm{dt}, \mathrm{J}=1.3 \mathrm{~Hz} ; 4.6 \mathrm{~Hz}, 1 \mathrm{H}, \mathrm{H}^{3}\right), 6.80(\mathrm{~d}$, $\mathrm{J}=1.6 \mathrm{~Hz}, 1 \mathrm{H}, \mathrm{H}^{1}$ ).

${ }^{13} \mathrm{C}-\mathrm{RMN}\left(151 \mathrm{MHz}, \mathrm{CDCl}_{3}\right): \delta(\mathrm{ppm})=20.5-20.7\left(\mathrm{C}^{8} ; \mathrm{C}^{10} ; \mathrm{C}^{12}\right), 61.5\left(\mathrm{C}^{6}\right), 64.4$ $\left(C^{4}\right), 66.9\left(C^{3}\right), 67.2\left(C^{2}\right), 73.2\left(C^{5}\right), 149.2\left(C^{1}\right), 169.9-170.4\left(C^{7} ; C^{9} ; C^{11}\right)$. 


\section{C) NMR data, representative products}

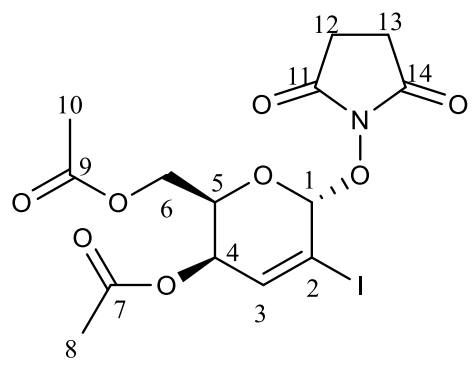

Mp: $150^{\circ} \mathrm{C}-151^{\circ} \mathrm{C}$.

${ }^{1} \mathrm{H}-\mathrm{RMN}\left(500 \mathrm{MHz}, \mathrm{CDCl}_{3}\right): \delta(\mathrm{ppm})=2.10-2.11\left(\mathrm{~s}, 6 \mathrm{H}, \mathrm{H}^{8,10}\right), 2.78(\mathrm{~s}, 4 \mathrm{H}$, $\left.\mathrm{H}^{12} ; \mathrm{H}^{13}\right), 4.07\left(\mathrm{dd}, \mathrm{J}=6.3 \mathrm{~Hz} ; 11.3 \mathrm{~Hz}, 1 \mathrm{H}, \mathrm{H}^{6}\right), 4.33(\mathrm{dd}, \mathrm{J}=6.3 \mathrm{~Hz} ; 11.3 \mathrm{~Hz}$, $\left.1 \mathrm{H}, \mathrm{H}^{6}\right), 4.90\left(\mathrm{td}, \mathrm{J}=2.7 \mathrm{~Hz} ; 6.3 \mathrm{~Hz}, 1 \mathrm{H}, \mathrm{H}^{5}\right), 5.08(\mathrm{dd}, \mathrm{J}=2.7 \mathrm{~Hz} ; 5.9 \mathrm{~Hz}, 1 \mathrm{H}$, $\left.\mathrm{H}^{4}\right), 5.68\left(\mathrm{~s}, 1 \mathrm{H}, \mathrm{H}^{1}\right), 6.96\left(\mathrm{~d}, \mathrm{~J}=5.8 \mathrm{~Hz}, 1 \mathrm{H}, \mathrm{H}^{3}\right)$

${ }^{13} \mathrm{C}-\mathrm{RMN}\left(126 \mathrm{MHz}, \mathrm{CDCl}_{3}\right): \delta(\mathrm{ppm})=.20 .6-20.8\left(\mathrm{C}^{8} ; \mathrm{C}^{10}\right), 25.5\left(\mathrm{C}^{12} ; \mathrm{C}^{13}\right)$, $61.5\left(\mathrm{C}^{6}\right), 64.5\left(\mathrm{C}^{4}\right), 67.4\left(\mathrm{C}^{5}\right), 94.2\left(\mathrm{C}^{2}\right), 101.8\left(\mathrm{C}^{1}\right), 137.9\left(\mathrm{C}^{3}\right), 169.9-$ $170.5\left(C^{7} ; C^{9}\right), 170.7\left(C^{11} ; C^{14}\right)$.

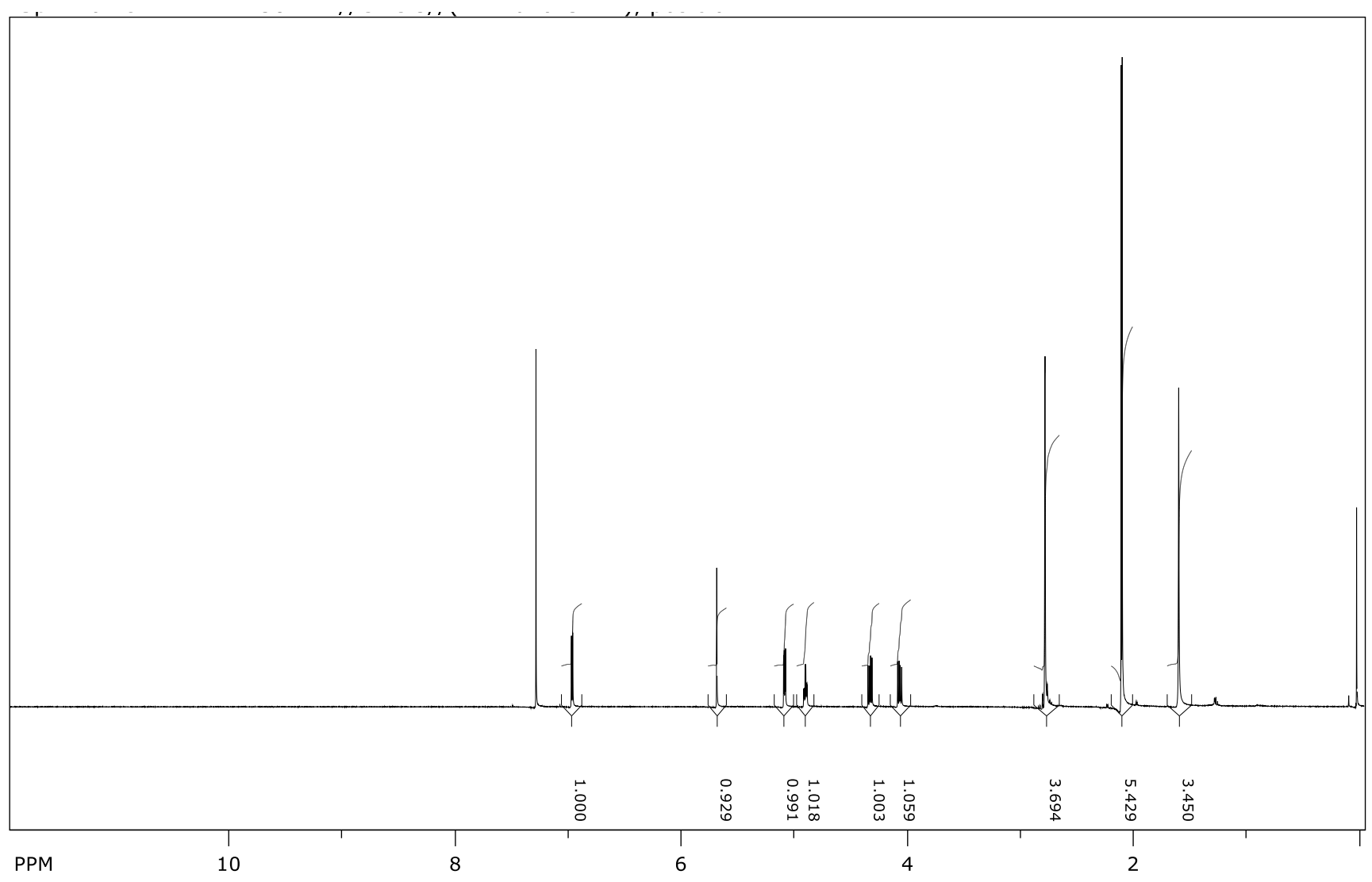



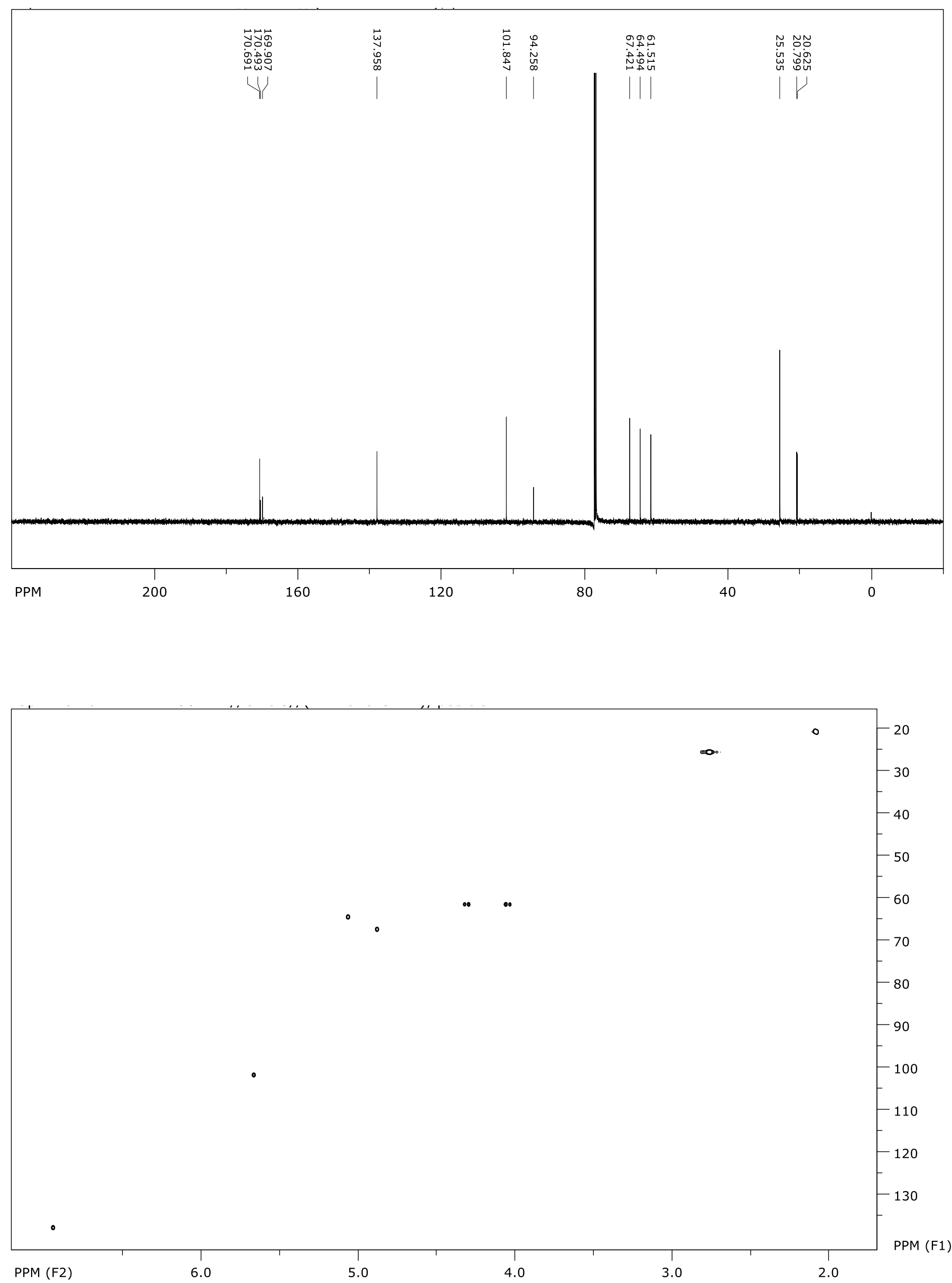


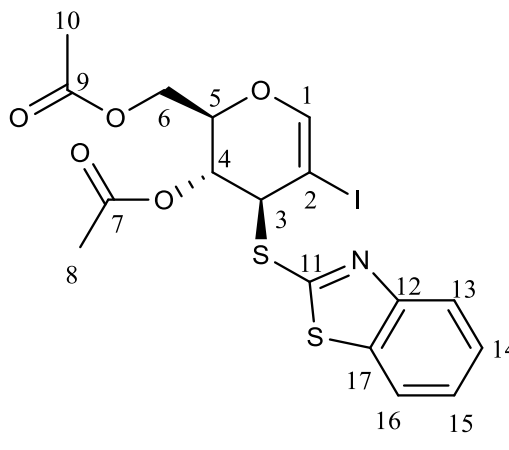

${ }^{1} \mathrm{H}-\mathrm{RMN}\left(500 \mathrm{MHz}, \mathrm{CDCl}_{3}\right): \delta(\mathrm{ppm})=1.56-2.10$ (s; s, $\left.6 \mathrm{H},-\mathrm{COCH}_{3}\right), 4.31-$ $4.36\left(\mathrm{dd}, \mathrm{J}=1.31 \mathrm{~Hz} ; 12.2 \mathrm{~Hz}, 1 \mathrm{H}, \mathrm{H}^{6}\right), 4.39-4.46\left(\mathrm{~m}, 2 \mathrm{H}, \mathrm{H}^{6}, \mathrm{H}^{5}\right), 5.23(\mathrm{~d}$, $\left.\mathrm{J}=4.4 \mathrm{~Hz}, 1 \mathrm{H}, \mathrm{H}^{3}\right), 5.63\left(\mathrm{dd}, \mathrm{J}=4.4 \mathrm{~Hz} ; 10.3 \mathrm{~Hz}, 1 \mathrm{H}, \mathrm{H}^{4}\right), 6.75\left(\mathrm{~s}, 1 \mathrm{H}, \mathrm{H}^{1}\right)$, 7.34 (ddd, J=1.2Hz; $\left.7.3 \mathrm{~Hz} ; 8.4 \mathrm{~Hz}, 1 \mathrm{H}, \mathrm{H}^{15}\right), 7.45$ (ddd, J=1.2Hz; $7.3 \mathrm{~Hz}$; $8.3 \mathrm{~Hz}, 1 \mathrm{H}, \mathrm{H}^{14}$ ), 7.78 (ddd, J=0.6Hz; $1.3 \mathrm{~Hz} ; 7.9 \mathrm{~Hz}, 1 \mathrm{H}, \mathrm{H}^{16}$ ), 7.87 (ddd, $\left.\mathrm{J}=0.6 \mathrm{~Hz} ; 1.2 \mathrm{~Hz} ; 8.2 \mathrm{~Hz}, 1 \mathrm{H}, \mathrm{H}^{13}\right)$.

${ }^{13} \mathrm{C}-\mathrm{RMN}\left(126 \mathrm{MHz}, \mathrm{CDCl}_{3}\right)$ : $\delta(\mathrm{ppm})=20.3-20.7\left(\mathrm{C}^{8} ; \mathrm{C}^{10}\right), 54.1\left(\mathrm{C}^{3}\right), 61.5$ $\left(C^{6}\right), 62.0\left(C^{2}\right), 65.9\left(C^{4}\right), 71.2\left(C^{5}\right), 121.1\left(C^{17}\right), 121.7\left(C^{13}\right), 124.8\left(C^{15}\right)$, $126.1\left(C^{14}\right), 135.3\left(C^{17}\right), 149.7\left(C^{1}\right), 152.6\left(C^{12}\right), 164.8\left(C^{11}\right)$ 169.2-170.5 $\left(C^{7} ; C^{9}\right)$.

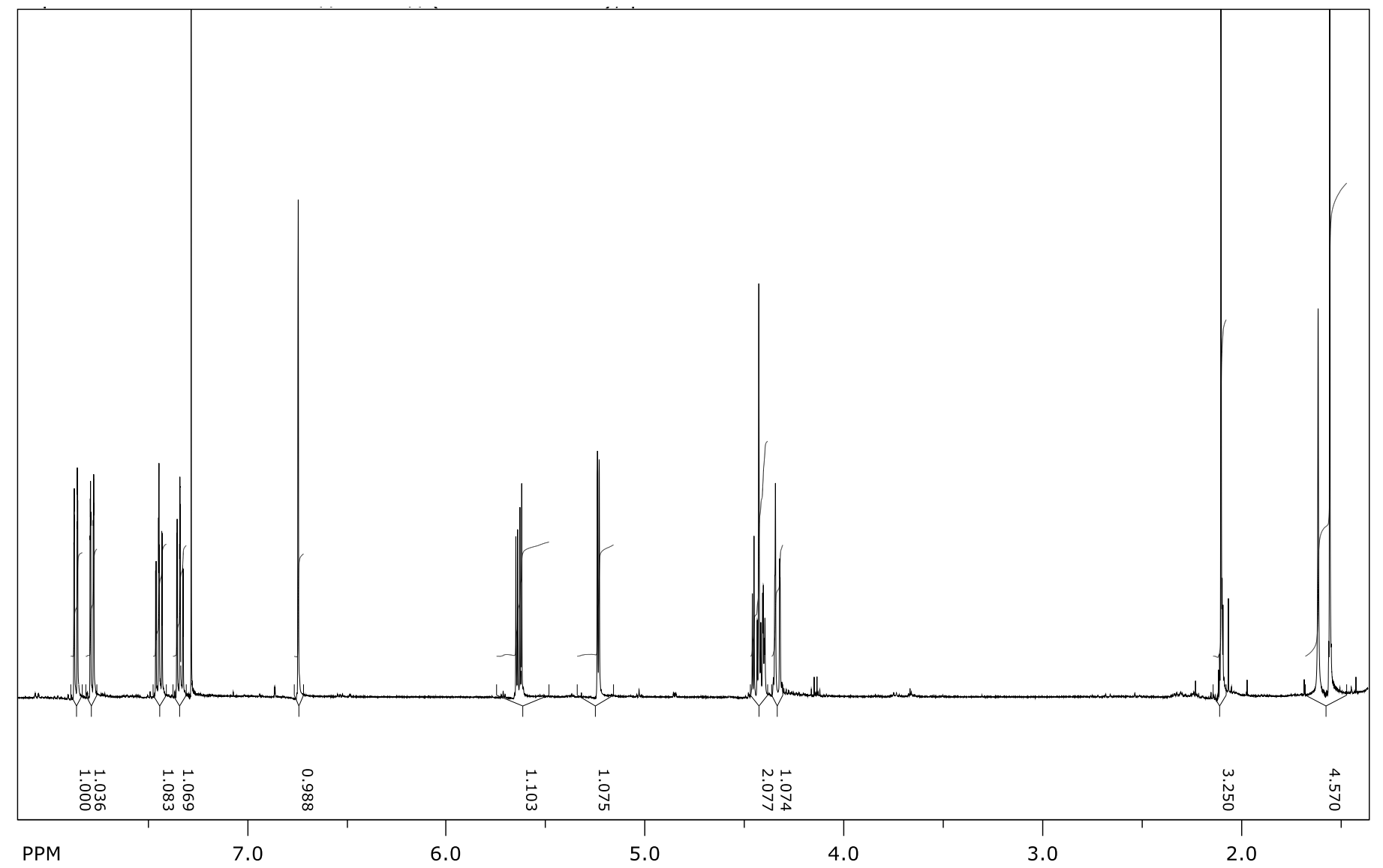



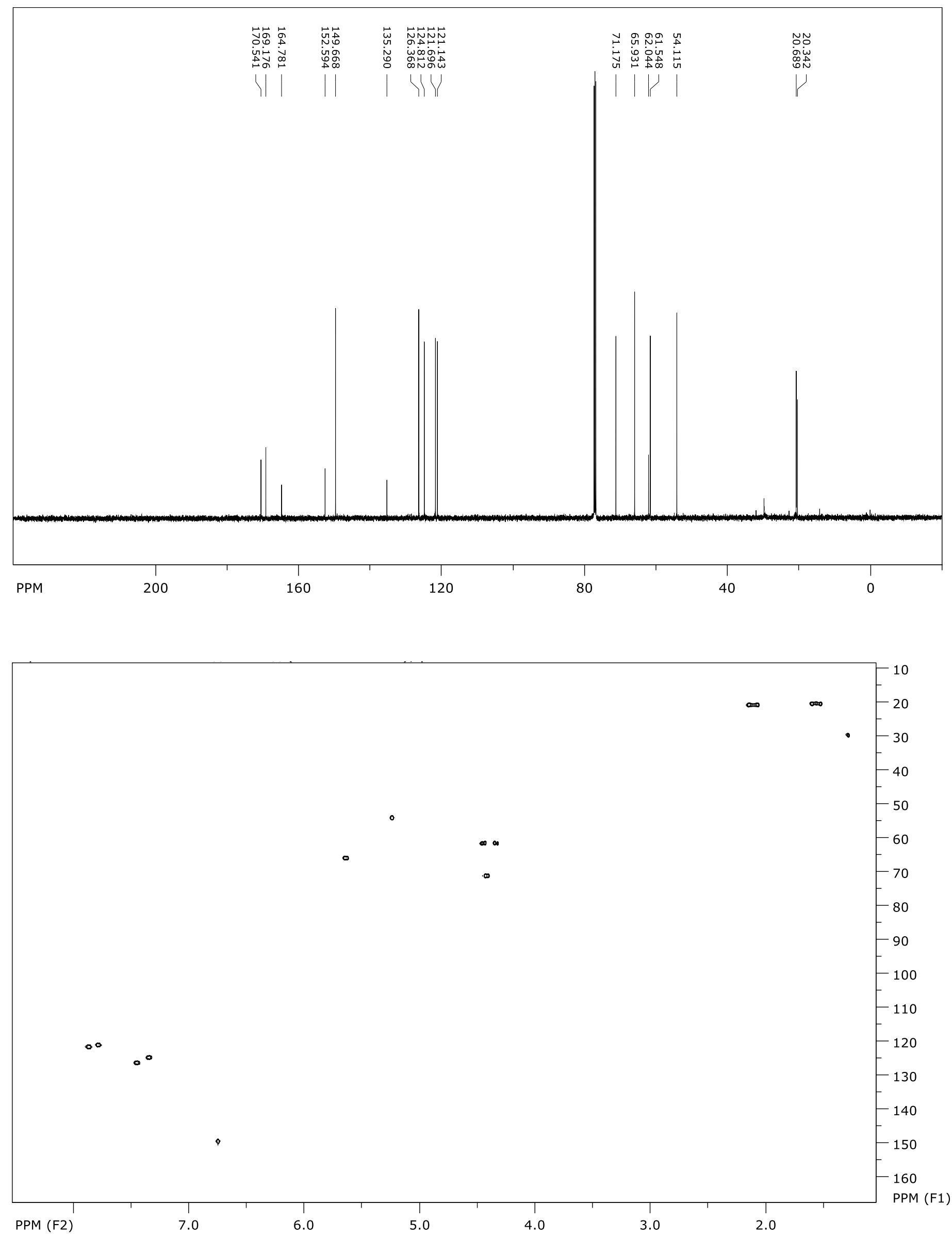